\title{
The "Journal of Functional Morphology and Kinesiology" Journal Club Series: Highlights on Recent Papers in Motor Control and Learning
}

\author{
Deepak K. Ravi ${ }^{1}$, William R. Taylor ${ }^{1}{ }^{(\mathbb{D})}$, Navrag B. Singh ${ }^{1}$, Brach Poston ${ }^{2}$, Christoph Mickel ${ }^{3}$ (D) \\ and Marinella Coco ${ }^{4, *}$ \\ 1 Institute for Biomechanics, ETH Zürich, 8093 Zürich, Switzerland; deepak.ravi@hest.ethz.ch (D.K.R.); \\ bt@ethz.ch (W.R.T.); navragsingh@ethz.ch (N.B.S.) \\ 2 Department of Kinesiology and Nutrition Sciences, University of Nevada Las Vegas, Las Vegas, NV 89154, USA; \\ brach.poston@unlv.edu \\ 3 Department of Human Movement Science and Athletic Training, Institute of Sports Sciences, \\ Goethe University, 60487 Frankfurt am Main, Germany; C.Mickel@sport.uni-frankfurt.de \\ 4 Italian Center Studies of Osteopathy, 95123 Catania, Italy \\ * Correspondence: marinella.coco@gmail.com
}

Received: 1 March 2018; Accepted: 1 March 2018; Published: 6 March 2018

\begin{abstract}
We are glad to introduce the sixth Journal Club. This edition is focused on several relevant studies published in recent years in the field of Motor Control and Learning, chosen by our Editorial Board members and their colleagues. We hope to stimulate your curiosity in this field and to share with you the passion for sport seen also from the scientific point of view. The Editorial Board members wish you an inspiring lecture.
\end{abstract}

Keywords: motor control; motor learning

\section{Introduction}

For several years, there has been an increasing interest in the study of Motor Control and Learning by the scientific community, which has been investigating and researching to find out the best definition, the most appropriate methodology and techniques, to best deal with this topic. According to the definition given by Adams, "learning" is a relatively permanent change in behavior performance or potentiality that can be acquired through observation or direct experience [1]. In 2007, Casolo identified two methods for assessing learning: measuring the time taken to correctly perform motor skills; and observing the learned movement quality as expressed in its effectiveness and precision [2].

In 2015, De Luca et al. proposed the "onion skin scheme" as the basic principle underlying human motor control. However, this new method has been criticized by some researchers, thus confirming that we are still far from an exhaustive knowledge of the subject.

Thanks to the innovative non-invasive method known as Transcranial Direct Current Stimulation (tDCS), which acts on specific brain areas, it is now possible to improve learning, both for rehabilitation and research purposes.

The knowledge of learning and motor control in healthy subjects has provided a clear and predictable framework that can also be applied in studies on subjects with disorders impairing motor function, as well as on individuals affected by genetic syndromes [3]. For this purpose, a three-year program (2016-2018) called "Enriched Sport Activities (ESA)", directed towards children with Down Syndrome from seven European countries, is currently being implemented. The ESA program aims at developing children's motor skills and improving their cognitive and social skills through various innovative sporting activities to promote social inclusion, equal opportunities and psycho-physical wellbeing. 


\section{Recent Papers Regarding Motor Control and Learning}

\subsection{Cerebral Palsy, Neuromuscular Development and Deficits, and Movement Variability}

Highlight by Deepak K. Ravi, William R. Taylor, Navrag B. Singh

Cerebral Palsy (CP) is the most common motor disability in children, and presents both neuromuscular and musculoskeletal impairments [4,5]. Children with $\mathrm{CP}$ have delayed and atypical motor development compared to age-matched healthy children, and the deficits are multifaceted. There is growing evidence from neuroimaging studies indicating that distinct deficits result from damage to specific neurological structures [6]. However, much less is known about the functioning of neuromuscular circuits underlying motor adaptation and learning in not only individuals with $\mathrm{CP}$, but also in typically developing children (TDC). As a result, treatment and rehabilitation of $\mathrm{CP}$ has been limited by a lack metrics that are sufficiently comprehensive for characterizing the skill development of healthy and pathological subjects. The fact that the brain additionally matures over childhood, makes it more complex to clearly elucidate the links [7]. Motor output variability (MoV) has gained increasing attention as a measure that is sensitive to differences in the quality of neuro-motor task performance and thus provides key information on the functionality of the Human Sensory Motor System (HSMS) [8]. MoV is appropriate for assessing simple repetitive functional tasks such as standing (balance) and walking, and is therefore practical for use in pathological populations. As such, neurophysiological models that are able to quantify the quality of movement output (rather than simple quantity), including $\mathrm{MoV}$, could therefore provide a key resource for understanding changes to the HSMS that occur as a result of either learning or adaptation, especially in the development of neural pathology.

Theories of motor control and learning postulate that neuromuscular variations occurring at the early development stage of a child facilitates adaptation and learning of motor skills [9-11]. During gait development, different maturation timelines may exist for adaptation of spatial and temporal parameters, possibly due to the structural maturation of corresponding brain circuits [12]. However, it remains unknown whether the adaptation of pathological populations is distinct from TDC. From this perspective, a recent study [3] has shown that neural control of limb-specificity during walking is preserved, even after injury in hemiplegic $\mathrm{CP}$, thus suggesting that therapies for correcting walking asymmetries is entirely possible in these populations. In their study, the pathological group exhibited marked differences in the adaptation patterns between the dominant and non-dominant limbs, which is in contrast to TDC. Importantly, compared to adults, pre-adolescent children have also been shown incapable of saving and re-learning adapted motor patterns unless they are provided with extended reinforced training such as robot-aided interventions [13]. Such traits have also been observed in children with hemiplegia, who have exhibited specific patterns of motor learning [14]. As a result, it now seems plausible that neuro-physiological models will soon be able to utilize such quantitative motor performance data as a foundation for understanding neuro-adaptive behavior [11].

In order to be successful and play a key role in understanding HSMS behavior and development, especially in pathological subjects, such models will need to overcome a range of critical challenges. Here, physiological constraints such as low muscle strength is known to play a negative role on the ability of $\mathrm{CP}$ children to adapt within a perturbed environment $[7,15]$. Ongoing research in our group aims to unravel the functioning of the HSMS in individuals with $\mathrm{CP}$, but this work also opens avenues for understanding the functional deficits in other neurological disorders such as Parkinson's disease, or adult fallers, by revealing the relationships between neuro-muscular deficits and functional motor performance. Such a comprehensive approach opens opportunities for exploring learning, adaptation, and degeneration of neuromotor skills over the lifespan of an individual. 


\subsection{Transcranial Direct Current Stimulation (tDCS) and Motor Learning}

Highlight by Brach Poston

Transcranial direct current stimulation is a non-invasive brain stimulation technique that has been shown to improve acute motor skill acquisition as well as longer-term motor learning in healthy adults when applied to brain areas such as the motor cortex (M1), dorsolateral prefrontal cortex (DLPFC), and the cerebellum [16]. Accordingly, it appears that about 3/4ths of the almost 50 available single session studies have reported that $\mathrm{tDCS}$ elicited motor skill acquisition increases either during or immediately after practice [16]. Furthermore, all 8 studies that have involved tDCS applied over multiple consecutive days have demonstrated increases in motor learning that were manifested either during the daily stimulation or after the stimulation period had ended [16]. However, it seems that all but one of these aforementioned studies involved relatively simple unilateral motor tasks of the hand and arm. Thus, very little research exists on the effects of tDCS on complex whole body motor tasks or bilateral tasks involving the upper limbs. Vancleef K. et al., in the manuscript entitled "tDCS over left M1 or DLPFC does not improve learning of a bimanual coordination task" [17], examined the influence of tDCS on motor learning of a complex bimanual tracking task involving the hand and wrist muscles. A total of 75 healthy young adults were randomized into 5 experimental groups ( $n=15$ per group). These groups included: (1) anodal tDCS of left M1 (a-M1); (2) SHAM tDCS of left M1 (s-M1); (3) anodal tDCS of left DLPFC (a-DLPFC); (4) SHAM tDCS of left DLPFC (s-DLPFC); and (5) a control group who performed the behavioral task with no stimulation of any kind applied (BEHAV). All subjects practiced the bimanual tracking task for $20 \mathrm{~min}$ a day over 4 consecutive days. In addition, a testing session was performed 7 days after the practice and stimulation sessions had ended to quantify retention of motor learning. The findings indicated that performance on the bimanual tracking task improved in all 5 groups over the course of the 4 days of practice, but there were no differences in task performance between any of the groups. Specifically, bimanual tracking task performance was similar for all the groups during the first day of training, over the 4 days of training, and in the retention session 7 days after practice and stimulation had ended (all $p$ values $>0.05$ ). Finally, measurements of motor evoked potential amplitude (an index of corticospinal excitability) that were taken in the a-M1 and s-M1 groups were also similar between these two groups of subjects $(p=0.41)$. In summary, the main findings of this study suggest that anodal tDCS of M1 and DLPFC fail to improve motor learning in a complex bimanual motor task in young adults to a greater extent than practice alone. These results suggest that tDCS may not be as efficacious in improving complex bimanual tasks compared with relatively simple unimanual tasks, although much more research is needed on these important issues.

\subsection{Motor Unit Recruitment and Rate Coding}

\section{Highlight by Christoph Mickel}

For many years, it has been known that the force production of a single muscle depends on neuromuscular activation and the muscular potential (morphology). A motor unit (MU)—also called the final common pathway [18] (Sherrington 1910)—is the smallest functional element of the motor control system and consists of a single motoneuron (MN) and the muscle fibers it innervates. While experiments on animals allow for direct measurements of $\mathrm{MN}$ characteristics and contractile properties, most studies on human subjects have relied on indirect measures, but with the advantage of the studied MUs being intact and within their physiological environment. Both animal and human model systems should be regarded as complementary. However, there have been examples where results from animal studies have not been able to be verified in human experiments. Nevertheless, there is no evidence that the basic principles of human and animal motor control differ [19].

The control of muscle force-and, therefore, movement in general-relies on two essential mechanisms: MU recruitment and rate coding. The so-called Henneman or size principle states that MNs are recruited in an orderly fashion from smallest to largest (e.g., [20]) when the muscle force 
is increased. In between the recruitment of further MUs, contractile force of the innervated muscle fibers depends on rate coding. The maximum tetanic force of each motor unit is reached at a certain firing rate, which has been shown to be inversely dependent on its twitch duration (e.g., [21]).

However, the aforementioned principles have been challenged by several authors over the last years, especially by a group of scientists led by Carlo De Luca, who have proposed the onion skin scheme as the basic principle underlying human motor control [22,23], but their results have also been criticized [24].

From my point of view, there are still plenty of new discoveries on collective MU behavior-especially at high force contractions-to come.

\subsection{Cognitive and Motivational Monitoring during Enriched Sport Activities in a Sample of Children Living in Europe. The ESA Program}

\section{Highlight by Marinella Coco}

Wang et al. describe the "Enriched Sport Activities (ESA)", a specific program co-funded by the EU Erasmus Plus Program (Key action: Sport-579661-EPP-1-2016-2-IT-SPO-SCP).

The three-year program is addressed to children with typical development and children with special needs (specifically children with asthma and children presenting with Down syndrome) aged between 6 and 14 years. ESA involves seven European countries: Italy [25], Germany, Portugal, Spain, Lithuania, Croatia and Turkey.

The ESA program aims at promoting physical activity as a tool to enhance social inclusion, equal opportunities and psycho-physical wellbeing.

The first phase of the program is focused on the direct participation of children, while a subsequent phase is aimed at parents who are, in fact, considered as the main source of engagement and stimulation for their children in practicing Physical Activity (PA).

The ESA program consists of 27 sports sessions which include: football, athletics, swimming, basketball and handball addressed to children with typical development, and Adapted Physical Activities (APA) devoted to children with special needs.

A duly trained Technical Expert Group (TEG) has the task of selecting a specific battery of tests useful to predict and monitor cognitive, social and motivational growth and provide parents with a tailored educational program.

Indeed, parents' knowledge and strategies need to be strongly improved so as to act more effectively at a psycho-pedagogical level by enhancing and encouraging children to practice sport activities.

ESA's final goal is the global development of children with typical development and children with special needs through sports practice.

Conflicts of Interest: The authors declare no conflict of interest.

\section{References}

1. Schmidt, R.A. A schema theory of discrete motor skill learning. Psychol. Rev. 1975, 82, 225-260. [CrossRef]

2. Casolo, F. Lineamenti di Teoria e Metodologia del Movimento umano; Vita e Pensiero: Milan, Italy, 2007. (In Italian)

3. Thomas, C.B.; Christopher, J.S.; Diane, L.D. Part 2: Adaptation of gait kinematics in unilateral cerebral palsy demonstrates preserved independent neural control of each limb. Front. Hum. Neurosci. 2017, 11, 50.

4. Rosenbaum, P.; Paneth, N.; Leviton, A.; Goldstein, M.; Bax, M.; Damiano, D. A report: The definition and classification of cerebral palsy. Dev. Med. Child. Neurol. 2006, 49, 8-14.

5. Graham, H.K.; Rosenbaum, P.; Paneth, N.; Dan, B.; Lin, J.P.; Damiano, D.L.; Becher, J.G.; Gaebler-Spira, D.; Colver, A.; Reddihough, D.S.; et al. Cerebral palsy. Nat. Rev. Dis. Primers. 2016, 2, 15082. [CrossRef] [PubMed] 
6. Meyns, P.; Van Gestel, L.; Leunissen, I.; De Cock, P.; Sunaert, S.; Feys, H.; Duysens, J.; Desloovere, K.; Ortibus, E. Macrostructural and microstructural brain lesions relate to gait pathology in children with cerebral palsy. Neurorehabil. Neural Repair 2016, 30, 817-833. [CrossRef] [PubMed]

7. Rose, J.; McGill, K.C. Neuromuscular activation and motor-unit firing characteristics in cerebral palsy. Dev. Med. Child Neurol. 2005, 47, 329-336. [CrossRef] [PubMed]

8. Singh, N.B.; König, N.; Arampatzis, A.; Heller, M.O.; Taylor, W.R. Extreme levels of noise constitute a key neuromuscular deficit in the elderly. PLoS ONE 2012, 7, e48449. [CrossRef] [PubMed]

9. Wu, H.G.; Miyamoto, Y.R.; Gonzalez Castro, L.N.; Ölveczky, B.P.; Smith, M.A. Temporal structure of motor variability is dynamically regulated and predicts motor learning ability. Nat. Neurosci. 2014, 17, 312-321. [CrossRef] [PubMed]

10. Manoel Ede, J.; Connolly, K.J. Variability and the development of skilled actions. Int. J. Psychophysiol. 1995, 19, 129-147. [CrossRef]

11. Takahashi, C.D.; Dan, N.; Christie, M.R.; Jennifer, K.L.; Dan, M.C.; David, J.R. Neuromotor noise limits motor performance, but not motor adaptation, in children. J. Neurophysiol. 2003, 90, 703-711. [CrossRef] [PubMed]

12. Vasudevan, E.V.; Torres-Oviedo, G.; Morton, S.M.; Yang, J.F.; Bastian, A.J. Younger is not always better: development of locomotor adaptation from childhood to adulthood. J. Neurosci. 2011, 31, 3055-3065. [CrossRef] [PubMed]

13. Kristin, E.M.; Ryan, T.R.; Ben, G.; Amy, J.B. Motor learning in childhood reveals distinct mechanisms for memory retention and re-learning. Learn. Mem. 2016, 23, 229-237.

14. Hermano, I.K.; Susan, E.F.; Dipietro, L.; Maria, F.P.; Richard, H.; Joel, S.; Neville, H. Motor learning characterises habilitation of children with hemiplegic cerebral palsy. Neurorehabil. Neural Repair 2012, 26, 855-860.

15. Meyns, P.; Van Gestel, L.; Bar-On, L.; Goudriaan, M.; Wambacq, H.; Aertbeliën, E.; Bruyninckx, H.; Molenaers, G.; De Cock, P.; Ortibus, E.; et al. Children with Spastic Cerebral Palsy Experience Difficulties Adjusting Their Gait Pattern to Weight Added to the Waist, While Typically Developing Children Do Not. Front. Hum. Neurosci. 2016, 10, 657. [CrossRef] [PubMed]

16. Buch, E.R.; Santarnecchi, E.; Antal, A.; Born, J.; Celnik, P.A.; Classen, J.; Gerloff, C.; Hallett, M.; Hummel, F.C.; Nitsche, M.A.; et al. Effects of tDCS on motor learning and memory formation: A consensus and critical position paper. Clin. Neurophysiol. 2017, 128, 589-603. [CrossRef] [PubMed]

17. Vancleef, K.; Meesen, R.; Swinnen, S.P.; Fujiyama, H. tDCS over left M1 or DLPFC does not improve learning of a bimanual coordination task. Sci. Rep. 2016, 6, 35739. [CrossRef] [PubMed]

18. Sherrington, C.S. Felxion-reflex of the limb, crossed extension reflex, and reflex stepping and standing. J. Appl. Physiol. 1910, 40, 28-121.

19. Piotrkiewicz, M.; Türker, K.S. Onion skin or common drive. Front. Cell. Neurosci. 2017, 11, 2. [CrossRef] [PubMed]

20. Henneman, E.; Clamman, H.P.; Gilles, J.D.; Skinner, R.D. Rank order of motor units within a pool: Law of combinations. J. Neurophysiol. 1974, 37, 1338-1349. [CrossRef] [PubMed]

21. Kernell, D. Principles of force gradation in skeletal muscles. Neural Plast. 2003, 10, 69-76. [CrossRef] [PubMed]

22. De Luca, C.J.; Contessa, P. Hierarchical control of motor units in voluntary contractions. J. Neurophyiosiol. 2012, 107, 178-195. [CrossRef] [PubMed]

23. De Luca, C.J.; Contessa, P. Biomechanical benefits of the onion-skin motor unit control scheme. J. Biomech. 2015, 48, 195-203. [CrossRef] [PubMed]

24. Farina, D.; Enoka, R.M. Surface EMG decomposition requires an appropriate validation. J. Neurophysiol. 2011, 105, 981-982. [CrossRef] [PubMed]

25. Alesi, M.; Silva, C.; Borrego, C.; Monteiro, D.; Genchi, R.; Polizzi, V.; Kirkar, M.; Demetriou, Y.; Brame, J.; Şahin, F.N.; et al. Cognitive and Motivational Monitoring during Enriched Sport Activities in a Sample of Children Living in Europe. The Esa Program. J. Funct. Morphol. Kinesiol. 2017, 2, 46. [CrossRef]

(C) 2018 by the authors. Licensee MDPI, Basel, Switzerland. This article is an open access article distributed under the terms and conditions of the Creative Commons Attribution (CC BY) license (http:/ / creativecommons.org/licenses/by/4.0/). 